This is an electronic reprint of the original article. This reprint may differ from the original in pagination and typographic detail.

Author(s): Käkölä, Timo

Title: $\quad$ Best practices for International eSourcing of Software Products and Services

Year: $\quad 2008$

Version:

Please cite the original version:

Kakola, T., "Best Practices for International eSourcing of Software Products and Services," Hawaii International Conference on System Sciences, Proceedings of the 41st Annual , vol., no., pp.17, 7-10 Jan. 2008 doi: 10.1109/HICSS.2008.71

All material supplied via JYX is protected by copyright and other intellectual property rights, and duplication or sale of all or part of any of the repository collections is not permitted, except that material may be duplicated by you for your research use or educational purposes in electronic or print form. You must obtain permission for any other use. Electronic or print copies may not be offered, whether for sale or otherwise to anyone who is not an authorised user. 


\title{
Best Practices for International eSourcing of Software Products and Services
}

\author{
Timo Käkölä \\ University of Jyväskylä \\ 40014 Jyväskylä \\ Finland \\ timokk@cc.jyu.fi
}

\begin{abstract}
This paper analyzes how the information and communications technology-supported international eSourcing of software products and services (IeS) can be effectively executed. The extant literature falls short of providing a systematic and detailed enough set of best practices to guide IeS. This paper presents best practices for IeS to facilitate further research, and to help managers and other stakeholders to understand, execute, and proactively improve and manage international eSourcing. The practices emphasize the need to establish and enact rigorous, mature, and quantitatively managed eSourcing lifecycles in order to transcend temporal, geographical, social, technical, and other boundaries in IeS.
\end{abstract}

Keywords: Functional size measurement, Global software development, International eSourcing, Knowledge management, Outsourcing, Software process improvement, Software project estimation and benchmarking

\section{Introduction}

The globalization of the world economy is putting increased pressure on companies to leverage information and communication technology (ICT) in order to become more competitive. The increasingly modular design and mature ICT have lowered the cost of managing global software development and offshore organizations have improved their capabilities [4]. As a result, ICT-supported international sourcing of software products and services (hereafter, "international eSourcing") has become an established way of doing software business $[4 ; 10 ; 33]$.

International eSourcing (IeS) refers to an ICT-enabled commercial arrangement, where an international outsourcing service consumer (hereafter, "IOSC" or "consumer") commissions a foreign provider (hereafter, "IOSP" or "provider") to provide software products or services formerly produced by the IOSC $[4 ; 8 ; 13 ; 33]$. Domestic eSourcing takes place within one country.

IeS is a risky undertaking shaped by temporal, language, geographic, social, cultural, historical, technical, and political boundaries [35; 39]. Unless all the boundaries are traversed, IeS is likely to fail $[12 ; 13 ; 26]$. A prerequisite for traversal is to understand the process of IeS. There are scientific works $[7 ; 13 ; 30 ; 39 ; 49]$ and international standards dealing with the process (e.g., $[17 ; 18])$. Yet, they do not provide a systematic and detailed enough set of best practices to help stakeholders execute IeS effectively. For example, Hefley and Loesche [13] recognize the importance of knowledge management for IeS but do not address ICT tool support for managing knowledge. Wu and Yalaho [49] present an IeS framework but argue for ICT tools such as agent technologies without justification, omit classes of tools important for process improvement (e.g., software project benchmarking and estimation systems), and do not address tool support in depth.

This paper presents a set of best practices to answer the question: How can software products and services be produced effectively through an IeS life-cycle? The set addresses four subquestions, which only $\mathrm{Wu} \&$ Yalaho [49] have covered holistically: (1) What are the phases of the IeS and how are these phases executed? (2) What are the major activities in each phase and how are these activities managed? (3) What are the performance measures and expected outcomes of each phase? (4) Which ICT tools best support the life-cycle and each phase?

The next section presents the practices for IeS. Section "Conclusions and future research" presents the conclusions, limitations, and future research issues.

\section{The set of best practices}

The set of best practices for IeS is presented in Figure 1 . It has been iteratively synthesized by conducting literature reviews, making drafts of the set, presenting them and collecting feedback from practitioners in industrial seminars, revising the drafts, writing versions of this article, having them reviewed by academic and industrial experts, and revising the article to ensure practical relevance and scientific rigor. Ten experts from five countries have reviewed the versions (see Section "Acknowledgments").

The practices draw upon the frameworks presented in [13, 30, 33, 49]. Hefley and Loesche [13] identified four eSourcing phases: analysis, initiation, delivery, and completion. The analysis and initiation phases are poorly enacted by most IOSCs. In the set of best practices, we revise the seven-phased life-cycle of $\mathrm{Wu} \&$ Yalaho [49]. The analysis phase corresponds with the strategic sourcing analysis and decision phase in Figure 1. The initiation phase is divided into four phases: 1 . international market research and promotion; 2. selection of providers; 3 . 
contract negotiation; and 4. project implementation. The "managing the eSourced services and the relationship" and "evaluation and contract termination" phases represent, respectively, the delivery and completion phases.

Ongoing management practices are enacted across the life-cycle [13]. Some ongoing practices take place at the level of a specific sourced service and deal only with the $\operatorname{IOSP}(\mathrm{s})$ of that service. Others take place at the organizational level and deal with all IOSPs and sourced services. Due to space limitations, a comprehensive coverage of the ongoing practices is beyond the scope of this paper.

The main activities and related performance measures, expected outcomes, and supporting ICT tools have been identified for each phase (c.f., [49]). The measures are presented to specify what the expected outcomes of each phase are, to review the expected outcomes according to the factual outcomes, and to set improvement targets [30]. A rectangular box on the top of Figure 1 represents the ICT infrastructure utilized in all the phases. The main activities are stated from the perspective of the IOSC.

\section{Phase 1: Strategic sourcing analysis and decision}

In this phase, the IOSC studies sourcing opportunities and decides the ratio between in-house development, domestic eSourcing, and IeS that it expects to be ideal.

\section{Main activities}

Setting business objectives and breaking them down into process objectives that pertain to the services being sought. To set realistic objectives and manage risks, the IOSP needs to understand systemically the business processes and the subprocesses and interfaces [24; 25].

Carmel \& Agarwal [4] presented a four-stage model of IeS: offshore bystander (i.e., domestic eSourcing), offshore experimenter, proactive cost focus (i.e., seeking IOSPwide leverage of cost efficiencies), and proactive strategic focus (i.e., viewing IeS as a strategic imperative). Kaiser $\&$ Hawk [22] added the fifth stage: strategic co-sourcing where the IOSP can replace or augment IOSC's ICT competencies. Only companies deploying ICT for competitive differentiation should aim at fourth or fifth stages [4].

Establishing a centralized eSourcing team to administer the analysis, select the IOSP(s), and develop and manage the relationships through ongoing organizational level practices $[9 ; 13 ; 37 ; 39 ; 49]$. The team should include members from the information systems division, key user groups, and executive management [37].

Identifying core competencies and eSourceable processes to decide which ICT services must be retained for operational or strategic reasons $[7 ; 9 ; 13 ; 27 ; 49]$ and to scope the sourcing analysis most appropriately.

Benchmarking eSourceable processes externally against world-class level companies that offer similar services or products (c.f., [13]) and/or internally against a reference model such as CMMI [1, 5] or the ISO 15504 (SPICE) standard [17]. Process benchmarking facilitates (1) aware- ness of all possible strategic alternative courses of action and their likely consequences and (2) the practical implementation of the chosen process improvement path [25]. The representations of baselined processes (e.g., process models and lessons-learned documents) must be documented and maintained in the organization's process asset library $[5 ; 25]$. Benchmarking is crucial to ensure that IOSCs do not waste time and money in eSourcing when their processes are so immature that even the requirements cannot be specified clearly $[4 ; 13 ; 29 ; 39-41]$.

Economical valuation. If the team finds eSourcing applicable, it will proceed to economical valuation [27; 37]. In the software development eSourcing context, the team will identify the scope of requirements for all pieces of software that can be eSourced within the planning period, and estimate the total work effort necessitated by the realization of the scope and the productivity and operating costs of in-house software production activities with respect to the specified scope. The functional sizes of all pieces of software to be produced are measured in function points by using standardized functional size measurement methods [19]. Function points express the amount of business functionality an information system provides to users, independent of the technology used to implement the information system [14].

The total work effort in man hours is estimated by multiplying the total functional size of the software to be produced with the project delivery rate of the in-house development organization. The rate is assessed in terms of the average number of development hours required in similar past development projects to deliver a function point [34; 43 ; 44]. A common method for analyzing operating costs for software production is activity based costing $[9 ; 44$; 49]. Utilizing the cost information and the estimated total work effort, the IOSC can estimate how much it would cost to produce eSourceable software in-house during the planning period. Software project benchmarking and estimation tools and databases $[14 ; 16 ; 28 ; 34 ; 38 ; 43]$ can then be used to benchmark the internal delivery rates and production costs with those of best-in-class local providers and IOSPs and see whether the production can be done most cost effectively by the IOSPs.

The strategic sourcing decision cannot be justified solely by evaluating the impacts of eSourcing on the development or maintenance costs. Revenues, life-cycle costs (including the transaction costs which are much higher in IeS than in domestic eSourcing and insourcing contexts), and the timing and uncertainties of all revenues and costs generated by eSourceable products and services need to be accounted for [37]. For example, more certain revenue sooner is better than less certain revenue later. Wesselius [23, Ch.2] probes why and how all these factors must be accounted for in economical value-driven software engineering. Assumptions and expectations of the future need to be captured explicitly through strategic scenarios. The scenarios must indicate that the volume for internationally 
eSourceable production is likely to be large enough and materialize quickly enough to cover investments necessary for building international eSourcing relationships. Based on the scenarios, projections of future costs and economical value can be made. The eSourcing team can then conclude whether to continue in-house development, backsource eSourced activities, eSource domestically, and/or eSource internationally. By doing these projections, the team will understand the current operational effectiveness and have a baseline for contract negotiations.

Engaging an external expert team to provide brokering and guidance $[9 ; 37 ; 39 ; 40]$. Functional sizing of the software typically needs to be performed by outside experts to ensure nonbiased and accurate sizing [34; 43]. The team having specific functional size measurement, benchmarking, contracting, domain, and eSourcing expertise can help the IOSC throughout the eSourcing life-cycle.

\section{Performance measures}

The criteria to be measured can be expressed with the following questions (c.f., [49]). Does the IOSC have a clear roadmap for the applications and services needed during the planning period - which applications and services will be needed, why, and when? Can it organize the eSourcing team, obtain adequate and valid market and inhouse information, identify core competencies, benchmark and baseline its eSourceable processes through performance measures such as software development productivity, estimate the future economical values of available alternatives, establish the processes needed to manage eSourcing, and identify and engage an expert team?

\section{Expected outcomes}

If the company decides to eSource, this phase is expected to deliver a set of defined business objectives and the business plan [37]. The plan may include a brief description of the eSourcing project, technical feasibility, resource requirements, estimated duration, and economical valuation of the project. The decisions taken include: the degree of eSourcing - total (i.e., more than 80 percent of the ICT budget) or selective, the period of eSourcing long term or short term, the number of IOSPs - single or multiple, and the type of eSourcing - service or software product development eSourcing $[7 ; 13 ; 26]$.

\section{Supporting ICT tools}

Companies use the following classes of tools for strategic sourcing analysis and decision making. Baselined and documented software and systems engineering processes need to be kept in the process asset library for process improvement. Decision (DSS) and executive support systems (ESS) may be used [20; 49] to assess eSourcing strategies, opportunities, threats, and resource requirements and to manage projects, services, and relationships. Software benchmarking and estimation tools help systematically collect, analyze, and report effort, cost, and functio- nal size data from all internal and eSourced projects. They need to be commercially available and compatible with the international benchmark repositories [16] and with the DSS and ESS tools relying on the collected data. The IOSC and the IOSP(s) can then utilize compatible benchmarking tools and better align their processes.

\section{Phase 2: International market research and promotion}

The next step is to identify the best candidate countries for eSourcing and to attract prospective IOSPs $[31 ; 32$; 49]. IeS is increasingly characterized by the concept of reverse markets [10], implying that IOSCs compete heavily over the opportunities to work with the best IOSPs.

\section{Main activities}

Assessment criteria need to be defined, reviewed, and approved by appropriate stakeholders to analyze the political, social, and legal environment of target countries. The following criteria should be considered $[2 ; 33 ; 36]$ : stability of the political and social environment, the attitude of the target country's government towards foreign ICT-related investments, production costs, size of the pool of software professionals, existence of a common language between the IOSC and the IOSP, feasibility of around-the-clock development, availability of functional and secure ICT infrastructure, laws for intellectual property protection, and export restrictions. Additionally, the ethical and political openness of the consumer country towards IeS to the target countries need to be assessed.

Identifying and selecting prime candidate countries and creating an initial list of prospective IOSPs.

Creating awareness. The IOSC publishes articles, offers, classified advertisements, and press releases in trade sites and mailing lists, newsgroups, and other outlets to attract prospective IOSPs [31].

\section{Performance measures}

Performance measures include the review and approval of the selection criteria by the stakeholders, the number of countries and IOSPs the IOSC has investigated, the number of promotion channels the IOSC has used, and the number of prospective IOSPs aware of the IOSC.

\section{Expected outcomes}

The IOSC expects to have the specific assessment criteria that have been reviewed and approved by the stakeholders, an extensive overview of the prospective countries, an initial list of prospective IOSPs, and an adequate level of awareness of the IOSC amongst the prospective countries and IOSPs.

\section{Supporting ICT tools}

The best candidate countries and IOSPs can be found by utilizing repositories and data collection methods such as industry specific databases, trade statistics databases, 
country related market databases, search engines, and trade sites on the Web [32]. ICT tools for international promotion include Web-casting, banner advertising, video on Extranet, and auto-responders [32; 49].

\section{Phase 3: Selection of providers}

The selection of IOSP(s) is the most important phase $[33 ; 49]$. However, most IOSCs do not have the resources and the expertise to perform this phase and the previous phase in-house. Such IOSCs should thus establish and leverage joint service providers for these two phases.

\section{Main activities}

Selection and evaluation criteria need to be defined, reviewed, and approved by appropriate stakeholders before investigating and selecting the IOSPs. Besides pricing, other characteristics of an IOSP must be considered:

- Experience and performance against defined quality and process objectives on previous eSourcing projects. Essential indicators are the CMMI and SPICE models measuring the IOSP's process capability to improve its product quality, productivity, predictability and cycle time $[5 ; 17]$. For highly rated IOSPs, the IOSC should check references [37].

- Human and technology resources [49, p. 79].

- The physical presence and the availability of substantial assets of the IOSP in the IOSC's home country facilitate communication, reduce cultural differences, and mitigate contractual risk by ensuring in the events of serious trouble that the IOSC can seek legal relief in local courts and reach the assets to satisfy judgments $[2 ; 39 ; 40]$.

- Cultural fit $[8 ; 49]$.

Identifying prospective IOSPS by reviewing the results of formal audits or assessments conducted against the IOSPs' quality management systems [1]. It is important to achieve consensus on the final list of IOSPs from relevant stakeholders and ensure a consistent understanding of the decision and its implications. The reviews provide limited information about the cultural fit or financial strength and thus need to be complemented with other methods. Results of the reviews should be used as a baseline (1) in the contracting phase to create incentive schemes that foster process improvement in the areas most important for the IOSC and reward the IOSP for timely high-quality deliveries and (2) in subsequent phases to monitor and improve processes of the selected IOSP [1].

Issuing a request for proposal (RFP) to the prospective IOSPs [37]. The RFP is a request that solicits detailed information on how and under which constraints the IOSP will perform its responsibilities, if selected. It should address the reasons to eSource, the scope and definitions of products and/or services to be eSourced, required IOSP qualifications, pricing per delivered function point, and detailed questions [9, p.188; 34; 37; 43].

Inviting bidders to a bidders' conference and organizing it at the IOSC's site [37] to ensure the bidders are fully cognizant of the contract requirements.

Comparing and ranking the proposals against preestablished and fully documented criteria [13; 37]. The eSourcing team conducts diligence activities to verify the IOSPs' capabilities based on the business objectives and prepares a detailed strategy for contract negotiation.

Selecting the IOSPS. A single IOSP can seldom meet all the needs whereas managing many IOSPs can be challenging. It is usually most effective to build close longstanding relationships with a few IOSPs $[4 ; 13 ; 40]$.

\section{Performance measures}

Performance measures include the review and approval of the defined selection and evaluation criteria by stakeholders; the definition, documentation, and approval of the RFP by the stakeholders; the correctness and comprehensiveness of requirements specified in the RFP with respect to the objectives; the diligence to verify IOSPs' capabilities; and the number of examined proposals.

\section{Expected outcomes}

The IOSC expects to have the defined evaluation criteria that have been reviewed and approved by the stakeholders, a completed RFP, a list of candidates that have been scored and ranked, low risks associated with the selected IOSPs, an overview of the IOSPs' capabilities, a secured access to the capabilities, compatibility with the IOSPs, and the eSourcing solution.

\section{Supporting ICT tools}

Process benchmarking using standard appraisal methods can provide a few thousand data points for a project [1]. Several projects of each potential IOSP must be analyzed. The evidence data is confidential, the anonymity of data sources must be secured, and all data needs to be archived. The IOSC thus has to utilize appraisal tools and databases to collect and store both documentary and interview evidence, relate the evidence with the model practices of the chosen reference model, report findings such as strengths and weaknesses of the appraised process areas, report model coverage by collected evidence, manage baselines, and leverage the secure benchmarking knowledge for process improvement $[1,42]$. Software project benchmarking and estimation tools are critical for benchmarking costs and cycle times [21]. Search engines can be utilized to collect information from IOSP [33; 49]. IOSPs must have sophisticated project, requirements, configuration, and test management systems to provide IOSCs with the information needed in the appraisals and bids.

\section{Phase 4: Contract negotiation}

The process of structuring the dynamics of the relationship begins in this phase $[27 ; 36 ; 49]$. There are two main contract types in IeS: framework contracts govern all projects throughout the relationship and project contracts 
deal with project specific issues [47]. Framework contracting is an ongoing practice making project contracting more effective because the stable aspects of a relationship need not be renegotiated for new projects. In the following, project contracts are primarily focused on.

\section{Main activities}

Defining legal and commercial terms, conditions, and property rights to represent negotiation topics and positions. The contract should include at least the following terms $[9 ; 11 ; 13 ; 27 ; 37]$ : scope of services, factors of production (e.g., people, skills, activities and "go/no go" decision points, deliverables and associated acceptance criteria, incentive and penalty systems, facilities, software, and third-party contracts), ownership of assets and the intellectual property rights to the software developed, service levels, performance measures, security provisions, transition and termination provisions, responsibilities (e.g., post-delivery maintenance) and governance, pricing, and schedules. In addition, it should define the escalation process for resolving conflicts, spell out the circumstances under which the escalation process and penalties are enacted, and include references to any standards or process models such as CMMI or ISO 20000 [18] which the IOSC wishes to impose on the IOSP.

Applying three contract types appropriately. (1) In software development context, contracting should be based on the agreed upon unit cost per function point $[34 ; 43]$. Fixed-price and time-and-materials contracting dominate in practice $[39 ; 40]$. But they tend to be too rigid for dealing with uncertainty in software development and thus may cause impaired eSourcing relationships. The unitcost-per-function-point contracting improves the relationships because of its fairness. (2) Fixed-price contracting should be deployed when requirements are clear [39] and deal with services or maintenance. Fixed prices limit IOSC's risk exposure and facilitate budgeting. But they are often unnecessarily high because the IOSPs may charge risk-premiums. (3) Short term time-and-materials contracts can be employed when requirements are still emerging [3; 39] and deal with services or maintenance.

Setting the negotiation baseline for the scope of delivery and the negotiation period. The software parts of the baseline must be measured and agreed upon in terms of function points to enable fair contracting [34; 43]: if the scope grows, the IOSP will be guaranteed extra compensation based on the number of additional function points delivered; if the IOSP fails to implement the baseline, sanctions can be based on the number of missing points.

Determining mutual commitments. Parties need to agree upon the business objectives and the role of the relationship in fulfilling them. To promote a mutual understanding of the commitments made, the IOSP must include on its negotiation team the person who will be responsible on-site for managing the service delivery [13].

Signing the contract.

\section{Performance measures}

Performance measures include the agreement of the legal and commercial terms, conditions, and property rights of the contract; the ability to specify the baseline scope of delivery; openness and collaborative effort of the IOSP during the negotiation [30, p.71], and the number of signed contracts versus the number of negotiated contracts.

\section{Expected outcomes}

The IOSC expects to have achieved a mutual agreement, embodied in a signed contract, with the IOSP on contract specifications, and have created a mutual ambition to aim for a win-win situation [30, p.71].

\section{Supporting ICT tools}

Contract databases are crucial to reduce the contracting risks and time [13; 49]. Software project benchmarking and estimation tools (see [16] for a review of commercial tools) facilitate baselining, scheduling, and pricing during contracting through effort, time, and cost estimations.

\section{Phase 5: Project implementation}

The goals and mutual commitments are refined and implemented by leveraging an implementation team [5].

\section{Main activities}

Building a joint cross-functional implementation team to manage implementation [5; 49]. For example, when an IOSC needs to re-engineer a business process by using a complex packaged software product but the product requires substantial configuration before meeting the needs, the solution is to involve the experts of in-house staff to understand the process, a system integrator to provide the application expertise, and the professional services of the vendor to provide the product knowledge [45].

Developing an implementation plan and agreeing upon the system development and/or service delivery process and tools. The parties should develop an implementation plan (i.e., a software development plan, a service plan, or a maintenance plan) detailing requirements, architectural interfaces and coupling between the system and its subcontracted parts, activities, deliverables, milestones for reviewing the deliverables, a process for tracking the performance metrics, and schedule $[9 ; 29 ; 32]$. The plan helps the team systemically understand the software or service process and make the managers aware of the coming changes and improvements.

Requirements development and management is a crucial part of implementation planning [39; 41]. When the IOSP is responsible for writing the requirements specification, the IOSC can validate relatively easily that the requirements have been understood correctly. To determine the software development project size in man months and the total cost, the functional size of the software estimated in the contract negotiation phase must be re-estimated based on the refined software requirements [34;43]. Functional 
sizing also improves the quality of the requirements because unclear requirements must be clarified for estimations, thus ensuring mutual understanding.

Training the employees of both parties. Software development codifies process- and application-related tacit knowledge into software in the form of complex and often nontransparent rules and structures [24]. The more tacit knowledge is codified, the more effort it takes to understand the software [24]. The learning curve is steep and expensive, but if a shared understanding of the software is not developed, the ground for an effective relationship is missing [33]. Ongoing provision of support and training will also improve project, relationship, and service delivery management skills [ $31 ; 49]$. Long-term relationships should be sought because short-term relationships may not offer enough time to pay back the investments.

Reporting technical progress by the IOSP to synchronize work and discover and solve problems quickly. When the IOSP is responsible for writing the reports, the IOSC can verify relatively easily that both parties are aware of the problems and have the same understanding about ways of resolving them and that the IOSP is acting upon the problems effectively. When the implementation team has finalized the first running software build in the software development eSourcing context, it should focus primarily on developing and evaluating the software releases succeeding on a regular basis $[3 ; 6]$.

Reviewing milestones together to verify progress against the planned schedule and deliverables, address emerging issues, and plan for next activities $[6 ; 29 ; 33 ; 40]$.

\section{Performance measures}

Performance measures include the review and approval of the implementation plan by stakeholders; the completion of training according to established plans; the completion of milestone reviews according to the planned schedule; and the completion of deliverables, including progress reports, according to plans and process objectives.

\section{Expected outcomes}

The IOSC expects to have more available funds and resources, a rational balance between in-house and eSourced production, an effective implementation team, a clear implementation plan, skilled and motivated employees, and high quality reporting and software deliverables.

\section{Supporting ICT tools}

The implementation team enacts a common systems development methodology and/or service delivery process using a compatible set of tools and data standards. Webbased project management, benchmarking and estimation, system development, reporting, training, and simulation tools improve implementation planning, the ability to quickly assemble teams, and the shared creation and use of software artifacts through centralized repositories, and enable appraisals for process improvement $[1 ; 33 ; 34 ; 38$;
41; 43]. Reporting needs diminish when the implementation team shares the artifacts through the repositories. Configuration management ensures the team members have the correct artifacts when needed [23, Ch. 14; 29; 40].

\section{Phase 6: Managing the eSourced services and the relationship}

Managing the services and the relationship well is crucial to achieve the benefits sought from eSourcing.

\section{Main activities}

Revising the management structure by creating the service management team. The best practices for IeS rely on a three-tiered management structure: senior management assigns the eSourcing team the responsibility for activities of the eSourcing life-cycle and oversees the relationships. During the implementation phase, the team establishes and directs the implementation team. Most IOSC's experts in the implementation team should be members of the eSourcing team. In this phase, a service management team is created that assumes managerial activities of the implementation team and supports the eSourcing team by managing the delivery of an eSourced service, the relationship, and the performance of the IOSP [13].

Effective sharing of knowledge. Partnerships should be established when the parties wish to evolve relationships toward strategic co-sourcing [22] and harmonize development processes, tools, and project management and service practices $[12 ; 15]$. The improvements raising the maturity of the IOSC's processes should be documented in the process asset library [5;24; 25]. In strategic R\&D partnerships [15] the parties should codify knowledge into and use reusable software components and platforms that raise productivity of future collaboration [23; 46].

Instituting performance metrics, monitoring mechanisms, and incentive, corrective action, and penalty systems aligned with the contract [27]. The metrics and mechanisms should have been specified in the implementation plan based on the strengths and weaknesses of the IOSP [1]. Effective metrics combine service levels with financial targets and include consequences associated with failure to meet minimum standards $[8 ; 27 ; 49]$. For example, function points are a viable metric because they are determined based on standardized measurement methods and represent true business value unlike metrics such as number-of-lines-of-code. A corrective action system should be in place as part of the quality management system to leverage the metrics in order to assess the IOSP's performance and to document and track deviations from performance targets through to closure [5]. Monitoring mechanisms such as periodical working-level meetings to monitor the IOSP's performance metrics should also be in place. The IOSP must have their own internal corrective action system to record and track all issues that come out of these meetings.

Performance monitoring is critical to provide incentives 
for improving eSourcing relationships. It ensures that the IOSP tracks all deviations and measures and reports about performance regularly, building confidence and enabling the IOSC not only to review progress but also to help the IOSP improve in the areas with the highest business impact $[5 ; 9]$. Whenever the IOSP's process capabilities increase significantly, the IOSC must update its appraisal database. Then it can benchmark the IOSP's performance against similar organizations and negotiate price reductions or improved service levels [13; 25; 26; 49].

Realigning the contract. The original contracts gradually become obsolete. Lengthy contract periods may thus be risky. The best length for a contract depends on what is being eSourced and why. Contract lengths of 5 to 10 years have been common for large U.S. based consumers [7, p. 9]. Some forms of renegotiations are thus necessary. The parties should be committed to the long-term relationship to help set realistic expectations [27].

Executing incentives, corrective actions, and penalties. The IOSC should provide incentives motivating the IOSP to exceed performance requirements and to send experts to work at the IOSC's site for limited periods. Tracked deviations should be corrected before they escalate. Penalties should be used only for extreme levels of noncompliance with the performance requirements.

\section{Performance measures}

Performance measures include the ability to create a culture matching the management structure; the quality of knowledge sharing; the compatibility of the development processes and environments of the parties; the number of reusable components and platforms developed jointly and the number of reusable components and platforms used; the institutionalization and enactment of incentive, corrective action, and penalty systems in accordance with the contract and the implementation plan; the institutionalization and enactment of the performance metrics and monitoring mechanisms in accordance with the implementation plan; and the validity period of the contract.

\section{Expected outcomes}

After reaching a stable relationship, the IOSC expects to have an effective management structure; a mutual commitment to a long-term relationship; effective knowledge sharing; institutionalized performance metrics, monitoring mechanisms, and performance monitoring; a realistic and fair contract; incentive, corrective action, and penalty systems; documented performance reports; and work products meeting the requirements on time and in budget.

\section{Supporting ICT tools}

Executive support systems that consolidate and analyze data from project management, benchmarking, and estimation systems and the usage logs of tools can be used to track the status of the relationship from multiple viewpoints (e.g., trends in productivity; amount and quality of communication enacted by using different tools). Executive support systems can also be used to track how many reusable components and platforms have been jointly developed and how many of them have been used in subsequent products and projects and to direct efforts to domains where such components can best be produced. The process asset library and the appraisal database are used, respectively, to document and assess improvements in IOSC's and IOSP's processes. The contract database is used to monitor contract compliance, analyze the needs for revisions, and store revisions.

\section{Phase 7: Evaluation and contract termination}

\section{Main activities}

Refining the evaluation criteria. The criteria established before selecting the IOSP should be used. However, the criteria concerning the deliverables may be elaborated because the stakeholders can now experiment with the software. For example, user satisfaction is often the true indicator of product or service quality [7]. The IOSC should thus include it in the evaluation criteria [49].

Evaluating products, services, switching costs, and the relationship. The IOSC checks the product or service deliverables against the terms of the contract. Relationship quality and switching costs determine, together with service and product quality, whether the relationship should be continued, alternative IOSPs should be sought, or the service or product should be backsourced. Relationship quality is characterized by factors such as trust, benefit and risk sharing, commitment, and conflict [48]. Switching costs are characterized by factors such as management structure upgrade costs, hiring and retraining costs, search and evaluation costs, and setup costs [48].

Postmortem analysis of the outcomes with respect to the contractual baseline helps uncover opportunities for improvement and highlights the activities that are performed effectively [6]. To improve future project and relationship management, the functional size, work effort expended, and total cost of the project, and information about the business domain and processes and tools used are stored in the software project benchmarking and estimation system. The results are compared to the estimates specified in the contract. The estimates of companies with mature processes tend to be close to the results. But most companies experience deviations, the reasons of which must be analyzed and documented [40]. The system can then be used in the future to derive more accurate estimates.

Documenting and storing the lessons learned in the process asset library help the IOSC manage eSourcing better and improve development, project management, and support processes through reusable process documents [5].

Making payments. In the software development eSourcing context, the IOSC makes payment on the functional size of delivered software. In general, financial reporting systems are used to determine payments. 
Assessing the alternatives. Based on the postmortem analysis and the evaluation of switching costs and product, service, and relationship qualities, the IOSC determines whether to extend the contract, switch IOSP(s), or backsource. The relationship should be continued if the IOSC perceives high switching costs and high levels of product, service, and relationship qualities. Backsourcing is usually the best option when the IOSC experiences low levels of switching costs and the three quality metrics [48]. Switching vendors is usually the best option when product and service quality are high but the relationship quality and perceived switching costs are low [48].

The relationship will terminate eventually $[7 ; 13 ; 30]$. The IOSC must thus be in touch with the eSourced competency area to enable substitution or backsourcing when the contract terminates. It must obtain all critical deliverables such as the source code to ensure smooth hand-off.

\section{Performance measures}

The measures include the technical performance of the product and/or service vs. the performance specified in the contract; the functional size of the product vs. the size estimated in the contract; the delivery time vs. the estimated delivery time in the contract; the cost of the project vs. the estimated cost in the contract; user satisfaction; relationship quality; switching costs; the degree of touch with eSourced competency area; and the ability to assess alternative sourcing arrangements [30].

\section{Expected outcomes}

The IOSC expects to have thorough knowledge of the performance of the IOSP and eSourced products or services; full satisfaction with the deliverables; ability to guide the future evolution of the product; ability to proactively improve the eSourcing life-cycle by leveraging the lessons learned; on-time delivery date; reduced phase-out costs; awareness of when to extend, switch or backsource; and thorough alignment with the business objectives and the strategic plan [30].

\section{Supporting ICT tools}

Evaluation of the IOSP and its services and products needs to be stored in the appraisal database to facilitate supplier selection and process improvement. The process asset library and the software project benchmarking and estimation system are used, respectively, to document improvements in internal systems development processes and to measure project performance for helping to predict future project performance.

\section{Conclusions and future research}

This paper developed a comprehensive set of best practices to advance eSourcing research and help IOSCs execute IeS successfully. The practices emphasize the need to establish and enact rigorous, mature, and quantitatively managed processes and methods that can help transcend the boundaries in international projects.

The set of practices has not been empirically validated through case studies or action research. However, it has been reviewed and partially validated by ten academic and industrial experts (see Section "Acknowledgments") and revised based on their feedback. Future theoretical and empirical research is needed to refine and further validate the set. It draws upon innovative methods such as software project benchmarking and estimation methods and systems, which have already been proven to work effectively in practice $[14 ; 21 ; 28 ; 34 ; 43]$ but have not yet been widely applied in the industry. Therefore action research is needed to help organizations (e.g., by means of training) move to the level of process maturity the practices call for. It is also important to examine whether the application of the practices helps companies move beyond the international eSourcing of simple tasks into long-term relationships where the most knowledge-intensive aspects of global software development are also shared.

Future research must examine how adoption of the practices can be eased. A staged representation similar to the staged representation of the CMMI may need to be developed to provide IOSCs with a roadmap through which they can raise the maturity of eSourcing by following a proven sequence of improvements, beginning with basic practices and tools and progressing through a predefined path of successive levels, each serving as a foundation for the next (c.f., [13]). If the adoption facilitates the move toward long-term relationships, then the companies can truly leverage the benefits and mitigate the risks of IeS.

\section{Acknowledgments}

The reviews of Carol Dekkers, Gary W. Dickson, Omar A. El Sawy, Erwin Engelsma, Inger V. Eriksson, Pekka Forselius, Peter Hill, Barbara Huisman, Jari A. Lehto, Risto Nevalainen, and the three anonymous reviewers greatly improved this paper.

\section{References}

1 Ahern, D. M., Armstrong, J., Clouse, A., Ferguson, J. R., Hayes, W., Nidiffer, K.E. (2005). CMMI® SCAMPI Distilled: Appraisals for Process Improvement. Addison-Wesley.

2 Apte, U. M. (1995). Globalization of Information Systems Outsourcing: Opportunities and Managerial Challenges. In J. Jurison \& C. Deans (Eds.), Information Technology in a Global Business Environment (pp. 307-321). Boyd \& Fraser.

3 Beck, K. \& Andres, C. (2004). Extreme programming explained: Embrace change, $2^{\text {nd }}$ Ed. Addison-Wesley.

4 Carmel, E. \& Agarwal, R. (2002). The Maturation of Offshore Sourcing of Information Technology Work. MIS Quarterly Executive, 1(2), 65-78.

5 Chrissis, M. B., Konrad, M. \& Shrum, S. (2003). CMMI®: Guidelines for Process Integration and Product Improvement. Addison-Wesley: SEI Series on Software Engineering.

6 Cusumano, M. \& Yoffie, D. (1998). Competing on Internet Time: Lessons from Netscape and Its Battle with Microsoft. The 
Free Press.

7 Dibbern, J., Goles, T., Hirschheim, R., Jayatilaka, B. (2004). Information Systems Outsourcing: A Survey and Analysis of the Literature. DATA BASE, 35(4), 6-102.

8 Goo, J., Kishore, R., \& Rao, H.R. (2004). Management of Information Technology Outsourcing Relationships: The Role of Service Level Agreements. Proceedings of the $25^{\text {th }}$ ICIS Conference, Washington, D.C., USA, 325-338.

9 Greaver, M. F. (1999). Strategic Outsourcing: A Structured Approach to Outsourcing Decisions and Initiatives. American Management Association.

10 Hagel, J. \& Brown, J.S. (2005). The Only Sustainable Edge: Why Business Strategy Depends on Productive Friction and Dynamic Specialization. Harvard Business School Press.

11 Heeks, R. (1996). Global Software Outsourcing to India by Multinational Corporations. In P. Palvia, S. Palvia \& E. M. Roche (Eds.), Global Information Technology and Systems Management: Key Issues and Trends (pp. 365-392). Ivy League.

12 Heeks, R. Krishna, S., Nicholson B., \& Sahay, S. 2001. Synching or Sinking: Trajectories and Strategies in Global Software Outsourcing Relationships. IEEE Software 18, 2, 54-60.

13 Hefley, W.E., \& Loesche, E.A. (2006). The eSourcing Capability Model for Client Organizations (eSCM-CL): Model Overview, V 1.1. Carnegie Mellon, http://itsqc.cs.cmu.edu/. 14 Hill, P. (2005). Practical Project Estimation, $2^{\text {nd }}$ Edition. International Software Benchmarking Standards Group.

15 Hoch, D., Roeding, C., Purkert, G., Lindner, S., and Mueller, R. (1999). Secrets of Software Success: Management Insights from 100 Software Firms Around the World. HBS Press.

16 ISBSG (2006). International Software Benchmarking Standards Group, http://www.isbsg.org/.

17 ISO (2004). ISO/IEC 15504 Information technology-Process assessment-Part 1: Concepts and vocabulary. International Organization for Standardization, http://www.iso.org.

18 ISO (2005). ISO/IEC 20000 Information technologyService management-Part 1: Specification. International Organization for Standardization, http://www.iso.org.

19 ISO (2006). ISO/IEC 14143 Information technology-Software measurement-Functional size measurement-Part 6 . International Organization for Standardization, http://www.iso.org.

20 Iver, R. K., \& Schkade, L. L. (1995). Management Support Systems for Multinational Business. In J. Jurison \& C. Deans (Eds.), Information Technology in a Global Business Environment: Readings and Cases (pp. 243-250). Boyd \& Fraser.

21 Jørgensen, M., \& Shepperd, M. (2007). A Systematic Review of Software Development Cost Estimation Studies. IEEE Transactions on Software Engineering, 33(1), 33-53.

22 Kaiser, K., \& Hawk, S. (2004). Evolution of Offshore Software Development: From Outsourcing to Cosourcing. MIS Quarterly Executive, 3(2), 69-81.

23 Käkölä, T. \& Dueñas, J. (Eds.) (2006).Software Product Lines: Research Issues in Engineering and Management. Springer. 24 Käkölä, T. \& Koota, K. (1999). Dual Information Systems: Supporting Organizational Working and Learning by Making Organizational Memory Transparent. Journal of Organizational Computing and Electronic Commerce, 9(2\&3), 205-232.

25 Käkölä, T. \& Koota, K. (1999). Redesigning ComputerSupported Work Processes with Dual Information Systems: the Work Process Benchmarking Service. Journal of Management Information Systems, 16(1), 87-119.

26 Lacity, M. C., \& Willcocks, L. (2001). Global Information Technology Outsourcing: In Search of Business Advantage.
Wiley.

27 Loh, L. (1994). An Organizational-Economic Blueprint for Information Technology Outsourcing: Concepts and Evidence. Proceedings of the $15^{\text {th }}$ ICIS Conference, Vancouver, Canada. 28 Maxwell, K.D. \& Forselius, P. (2000). Benchmarking Software Development Productivity. IEEE Software, 17(1), 80-88. 29 Mehta, M., \& Yadav, R. (2006). Project Mindset for Software Outsourcing. Project Perspectives, 28(1), 98-101.

30 Momme, J. (2002). Framework for Outsourcing Manufacturing: Strategic and Operational Implications. Computers in Industry, 49(1), 59-75.

31 Nahar, N. (2001). Information Technology Supported Technology Transfer Process: A Multi-Site Case Study of HighTech Enterprises. University of Jyväskylä, Finland.

32 Nahar, N., Huda, N., Tepandi, J., \& Nahon, K. (2001). International Software Production through Outsourcing Process. In R. Hackney (Ed.), Proceedings of the $11^{\text {th }}$ Annual Business Information technology (BIT 2001) Conference, Manchester, UK. 33 Nahar, N., Käkölä, T., \& Huda, N. (2002, May 29-31). Software Production in Developing and Emerging Countries through International Outsourcing. In S. Krishna \& S. Madon (Eds.), Proceedings of the 7th International Working Conference of IFIP-WG 9.4 (pp. 292-310). Bangalore, India.

34 NorthernScope (2007). NorthernScope: Customer-Driven Scope Control for ICT-Projects. FiSMA, http://www.fisma.fi.

35 Orlikowski, W. J. (2000). Knowing In Practice: Enacting A Collective Capability In Distributed Organizing. Organization Science, 13(3), 249-273.

36 Phillips, D. (2002). Selected Legal Issues in International Software Outsourcing. Licensing Journal, 22(8), 13-20.

37 Reid, W. S. (1996). Outsourcing: The 20 Steps to Success. http://www.wsrcg.com/Articles/OutSourcing.pdf.

38 Rollo, A., Morris, P., Wasylkowski, E. (2006). ISBSG Benchmarking Standard, Version 0.9. http://www.isbsg.org/.

39 Rottman, J., \& Lacity, M. (2004). Twenty Practices for Offshore Outsourcing. MIS Quarterly Executive, 3(3), 117-131.

40 Sakthivel, S. (2007). Managing Risk in Offshore Systems Development. Communications of the ACM, 50(4), 69-75.

41 Salo, A., \& Käkölä, T. (2005). Groupware Support for Requirements Management in New Product Development. Journal of Organizational Computing and Electronic Commerce, 15(4).

42 Software Quality Institute (2006). Appraisal Assistant. Griffith University, Australia. http://www.sqi.gu.edu.au.

43 SouthernScope (2000). SouthernScope Reference Manual. Government of Victoria, Australia. http://www.egov.vic.gov.au/. 44 Stutzke R. D. (2005). Estimating Software-Intensive Systems: Projects, Products, and Processes. Addison-Wesley.

45 Vandoren, V. J., \& Nowicki, P. (1999). Choosing the Right Project Implementation Strategy. Control Engineering, Barrington, 46(8), 41-44.

46 Van Der Linden, F., Schmid, K., \& Rommes, E. (2007). Software Product Lines in Action: The Best Industrial Practice in Product Line Engineering. Springer.

47 Warsta, J. (2001). Contracting in Software Business: Analysis of Evolving Contract Processes and Relationships. Ph.D. Dissertation. University of Oulu, Finland.

48 Whitten, D. \& Leidner, D. (2006). Bringing IT Back: An Analysis of the Decision to Backsource or Switch Vendors. Decision Sciences, 37(4), 605-621.

49 Wu, C., \& Yalaho, A. (2002). IT-Supported International Outsourcing of Software Production. M.Sc. thesis. University of Jyväskylä, Finland. 


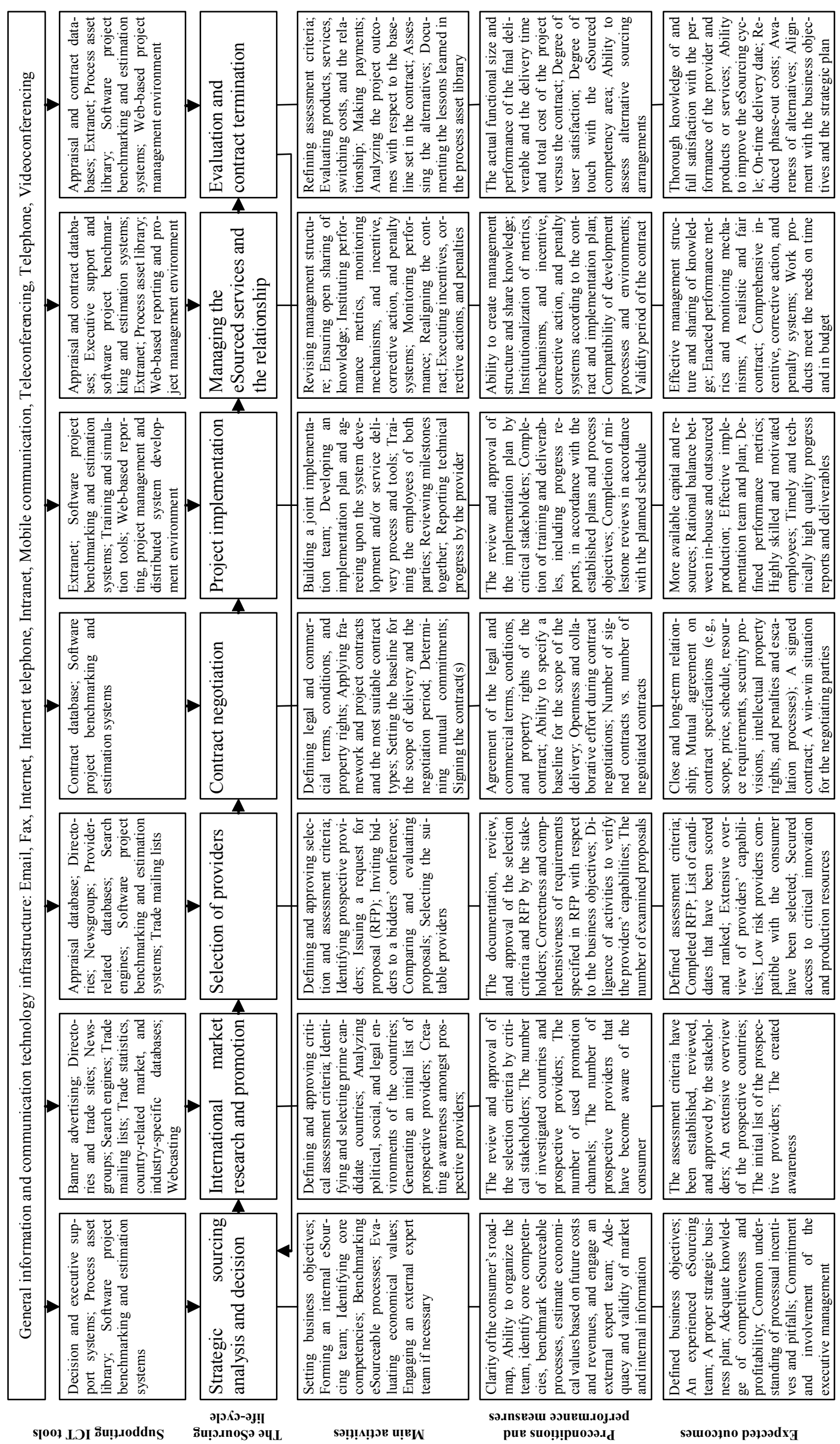

